Methods Development of the ROI taxonomies was fourfold. First, member groups of the International Life Saving Federation (ILSF) were contacted for access to any drowning related data taxonomies available to them. A comparison study of the different taxonomies accessed through the email campaign was then conducted. Analyses involved contrasting and comparing items from the selected taxonomies and identifying valuable details for inclusion in the ROI set. Materials relevant to an Irish context were then adapted, and the taxonomies created. Last, a host of ROI-based water safety experts reviewed the proposed taxonomies during an interactive stakeholder workshop. This was conducted using the Interactive Management (IM) methodology, and yielded valuable recommendations, which were then incorporated to produce the definitive set of drowning data taxonomies. Results A novel set of drowning data taxonomies were designed and completed. These were evaluated favourably during the stakeholder workshop, with any expert feedback acknowledged and incorporated.

Conclusions The quality of drowning fatality data records in the ROI can be improved by the current project activities. These taxonomies will be used to populate a drowning fatalities database, currently being designed in conjunction with this study. These will ultimately provide a high quality evidence base from which to inform intervention design in the ROI, and prevent further drowning fatalities.

\section{FROM ROLE OF THE SEARCHER DROWNING VICTIMS LEAD TO DROWNING PREVENTING IN THE COMMUNITY, NAKHON RATCHASIMA PROVINCE, THAILAND}

${ }^{1}$ Chanchai Supawerakul, ${ }^{2}$ Pisitpong Sirisupakul, ${ }^{1,2}$ Buddha Dhamma Hook. ${ }^{1}$ Section Chief of Underwater Rescue. ${ }^{2}$ Foundation's Nakhon Ratchasima, Thailand

\subsection{6/injuryprev-2016-042156.1016}

Background Nakhon Ratchasima is on the northeastern of Thailand with a largest area of the country and population, is the 2nd from the capital, Bangkok Metropolitan. Mainly area is the agricultural area, the several rivers flows through includes the canals have many the drilled pools and water wells for the local agricultural. The number of the deaths from 2008-2013 were drowned in a most of the country averaged 200 persons a year (with population rate per a thousand equal to 6.4-9.3) in this number were the children lower aged 15 years, averaged 47 children a year, the underwater rescue of Huk 31 caused gather into a group of volunteers networking with mainly role to seek for the drowning victims and was operated according to seeking for the drowning victims task from 1993 until the current found that more than 1000 victims that was informed and seek in the water have not one to be survival and the crime scene often found that is the nature water will in the community thus was caused of concept to preventing from the origin rather than solve an end up of the problem that is mean have no chance to survive.

Methods To stimulate the participation of the community in the prevention of drowning.

Started operation since 2012 by taught the children and those interested learning about water safety, how to survive by floating in the water and use the easily floating devices (Empty plastic bottles) that assists to buoyancy themselves and how to help the others from drowning in correctly by offered free course 1 time a month and build up the team networking of the community to surveying the risk water wills includes operate to manage the risk water wills in the community in Loy Krathong Festival and Songkran Festival by installed the warning Signs, fitting drowning rescue instruments too easily finding such as plastic gallons, filing beams, ropes, for the purpose that operating and instruments which using were from corporation of the public in the community and donation from the private sectors.

Results After operated, the student of Primary Education Level 1-6 trained practical part of 6,114 students, to be the instruction volunteers networking of 606 volunteers, offered free survival method from drowning 1 time a month totally of 35 times with the children, the guardians, the interested public of 350 persons, arranged the risk water will by the preventing the children from drowning networking of 90 water wills and operated covers the sub-districts of 32 districts of Nakhon Ratchasima Province furthermore found that notification to seeking the drowning victims was decreased.

Conclusions Drowning is preventable by the role of the searcher drowning victims that lead to drowning preventing in the community with operations in simple measures focused skills training for the children, creating the volunteers networking, manage the risk water wills under participation of the community It increases the chances of survival from drowning for the children in Nakhon Ratchasima Province.

\section{SUCCESS PROJECT ABOUT DROWNING PREVENTION BY VOLUNTEERS IN THE COMMUNITY, NAKHON RATCHASIMA POVINCE, THAILAND}

${ }^{1}$ Chanchai Supawerakul, ${ }^{2}$ Pisit Pongsirisupakul. 'Section Chief of Underwater Rescue, ${ }^{2}$ Foundation's Nakhon Ratchasima, Thailand

\subsection{6/injuryprev-2016-042156.1017}

Background Nakhon Ratchasima province is the largest province of Thailand. It has the second highest number of population (the first highest number of population is Bangkok). Its main areas are agricultural. Its statistical death of drowning, that usually occurs in rural areas and natural water sources, is in the top 10 provinces of Thailand.

Methods This project has been starting since 2012. To reduce The number of dead children from drowning in Nakhon Ratchasima povinces. It has been built by a network of well-promoter team comprising many sectors. This project has been based on the revision of existing experience and the own cost. This project was started from one team in the urban and then was expending to rural areas until it was completely covered the 32 districts in 2015. There are educations about safety on water for communities, skills about helping people from drowning, survival skills on the water when drowning and, skills for CPR. In addition, there are using the resources that are easy to find out in the area, build up communities network team to manage high-risk water sources and, installing warning sign with first aids for helping people from drowning.

Results According to the study, it is found that the number of children, who died from drowning (0-14 years) in Nakhon Ratchasima at the beginning of the year 2012, were 40 children (8.4). In 2013, there were 36 children(7.5) who died from drowning. In 2014, there were 23 children(4.8) who died from drowning. In 2015, there were 21 children(4.4)who died from drowning. The number of dead children from 2012-2015 has been decreasing because of the good cooperation between a network of well-promoter (32 teams of Nakhon Ratchasima) and management 90 places high-risk water sources. 
Conclusions Death from drowning can be prevented by creating a network team in the area, using the simple methods that focus on skill training for children and managing about environmental water resources under resources of the area.

\section{WOMEN'S PARTICIPATION IN ENSURING CHILDREN SAFETY-EXPERENCES FROM BANGLADESH}

${ }^{1}$ Asma UI Hosna, ${ }^{1} J a h a n g i r$ Hossain, ${ }^{1}$ Aminur Rahman. ${ }^{1}$ Centre for Injury Prevention and Research, Bangladesh (CIPRB)

\subsection{6/injuryprev-2016-042156.1018}

Background Drowning is the leading killer of children 1-4 year in Bangladesh, accounting for $43 \%$ of total child mortality in this age group. Lack of supervision, high exposure to water hazards, lack of education and poverty are some of the major risk factors for childhood drowning in Bangladesh. To ensure child safety from drowning in the rural areas 1600 Anchals (community crèches) were implemented during 2013-14 in three sub-districts of Bangladesh where children stay safely under supervision of two local caregivers (Anchal caregiver and her Assistant). In each Anchal 20-25 children aged 9 to 36 months, are kept between 9:00 am and 1:00 pm, six days a week. The objective of the study was to assess the women's participation in ensuring child safety through Anchal in rural areas of Bangladesh.

Methods A qualitative method was applied in this study. Last 17 months salaries of 3200 women were analysed and Focus Group Discussions (FGDs) were conducted with 100 Anchal caregivers in 10 groups in the three different locations to understand their position in the family and the society.

Results 3200 Women worked voluntarily to ensure injury safety of 35,000 children. From June 2014 to October 2015 (17 months) these women earned a total of BDT 5,40,96,890/- which made social, financial and economic changes in their lives. Community people respected them as teacher of the children. These women were more aware on injury prevention. The FGDs also found that independent earnings gave them a higher status in the family and as a result of that, the husband-wife interaction on decision-making increased. Five days basic training, monthly meetings and compliance training increased their mobility outside home and the social status of them. These women's communication skills had also increased.

Conclusions From the study it was found that women had been empowered and children's safety was ensured through the Anchal programme.

\section{RISK ASSESSMENT DURING THE ACTIVITY OF DOMESTIC BABIES AND YOUNG CHILDREN'S BATH - BATHRISK (ALICANTE, SPAIN, DATE PROJECT: JANURY - DECEMBER 2015)}

Ana M Sáncheza, Karina Pernías, Mari Cruz Arenas, Sonia Pinteño, Mari Carmen Hita. AIJU Tecnological Institute for Children'S Products and Leisure

\subsection{6/injuryprev-2016-042156.1019}

Background Drowning is the second leading cause of children's deaths and accidents due to unintentional injuries worldwide. There are a lot of products to facilitate babies and toddler's bath, but their risk of injury has been demonstrated. Most items for children are regulated by specific European standards but in the case of these articles for which there is no specific European safety legislation, there is a Decision of the European Commission of January 6, 2010. The main purpose is to analyse the risks associated with the activity of children (from 0 to 48 months) bathing at home by taking into account the child and caregiver's behaviour and characteristics of the children's products used.

Methods Search and analysis of scientific data on the epidemiology of childhood unintentional injuries related to the bath activity at home. Study and analysis of information from injuries databases. Experimental and simulation analysis of five bath scenarios for different ages. Development of recommendations. Guide of prevention and safety during children's bath.

Results Injuries in bathing vary with age, since the risks and circumstances, and therefore the type of unintentional injury, are closely related to the stage of development of the child. Other factors affecting these injuries are: physical environment in the bathroom, behaviour of caregivers, overcrowded housing and new products consumed during bath time.

Conclusions Most children's injuries that occur during bathing happen to babies from around 6-12 months. Bath-assisting devices causing problems are, in order: infant bath rings, baths or showers for adults and children's collapsible baths. The main causes of drowning injuries are also prioritised: leaving children unattended in the bath only 1-2 min, tipping over babies' bath seats, taking the suction cups off the child seats, climbing over the bath chair and falling overboard, or slipping through the leg openings of the chair thus falling in the water and choking on small parts of bath toys.

\section{CHILDREN'S UNDERSTANDING OF NO DIVING WARNING SIGNS: IMPLICATIONS FOR PREVENTING CHILDHOOD INJURY}

Barbara A Morrongiello, Amanda Cox, Rachel Scott, Sarah E Sutey. University of Guelph, Guelph Ontario, Canada

\subsection{6/injuryprev-2016-042156.1020}

Background Diving related injuries are often catastrophic and result in life altering effects for victims and their families. One common approach to alerting people to diving hazards and injury risks is through the posting of warning signs. Of course, whether warning signs are effective for these purposes depends in part on how well viewers understand the intended message. The current study examined children's understanding of various features of No Diving warning signs.

Methods Normally developing 7 to 10 year olds were asked questions to assess their understanding of text, images, and main messages on No Diving warning signs. These structured interviews were audio recorded and responses were later coded, with excellent resulting reliability (Kappa $=0.91)$.

Results Children understood the behaviour advised against (diving), why it is prohibited (can hit head on the bottom), and what can happen (serious injury including hospitalisation). They understood that breaking your neck results in limitations in mobility and can occur from diving, but they did not anticipate that such an injury is likely to occur. There were no gender and few age differences, but diving experience was associated with children significantly downplaying their risk of injury.

Conclusions Having No Diving warning signs explicitly mention a broken neck, may serve to remind children of this potential consequences at the time of decision making. Active adult supervision is particularly important for children who have prior positive diving experiences. 